\title{
China's M00C Research Hotspot Based on the Visual Co-Word Network Map: 1994-2018
}

\author{
Qiong Li \\ School of Public Administration, Jinan University, Guangzhou, China \\ Email: 297085859 @qq.com
}

How to cite this paper: Li, Q. (2018) China's MOOC Research Hotspot Based on the Visual Co-Word Network Map: 1994-2018. Open Journal of Social Sciences, 6, 151-163. https://doi.org/10.4236/jss.2018.69010

Received: August 8, 2018

Accepted: September 3, 2018

Published: September 6, 2018

Copyright $\odot 2018$ by author and Scientific Research Publishing Inc. This work is licensed under the Creative Commons Attribution International License (CC BY 4.0).

http://creativecommons.org/licenses/by/4.0/

\section{c) (i) Open Access}

\begin{abstract}
In this paper, based on CSSCI and SCI databases' published papers during 1994-2018 from the data source, we use co-word analysis and social network analysis to build the China's MOOC research visualization network map to describe the dynamic of the field, and suggest forecast for the future MOOC research. We found out that China's MOOC research focusing on MOOC development countermeasure research, MOOC educational information, classroom teaching and MOOC hybrid teaching, MOOC and open education resources, MOOC application research of the library in colleges. The future research focuses on the study of the humanistic value of MOOC education and the research on the hybrid teaching mode of classroom teaching and online teaching.
\end{abstract}

\section{Keywords}

China's MOOC Research, MOOC, Co-Word Network Map, Research Hotspot, Research Trends

\section{Introduction}

In 2014, China's Ministry Of Education positively developed the online education strategy, design the future top-level development system of online education, China University MOOC officially opened, online education like MOOC platform is expected to become the technical carrier to realized overtaking around the corner. Over the past 4 years, the study of MOOC in China has undergone a major transformation, we urgently need to know the current hot topic in the study of Chinese's MOOC and future trends, based on this, use co-word analysis, social network analysis to build the China's MOOC research visualization network map appear to be particularly important. So, we hope to provide data basis for researchers to grasp the latest research trends of MOOC. 
MOOC is the abbreviation of A Massive Open Online Course, which is a new online education mode aimed to achieve quality education resources unlimited open access to the remote. The term MOOC was coined by Dave Cormier of prince Edward island university in 2008, the course, CCK08 (Connectivism and Connective Knowledge course), was led by Stephen Downes is the first MOOC in real meaningful (Zancanaro et al., 2018) [1]. Meanwhile, a large number of online learning platforms for social learners, such as khan academy, P2PU, Udemy and ALISON, have emerged outside the university's organizational system (Multon et al., 2018) [2]. 2012 is a crucial year for education modernization. With the arrival of the first year of world MOOC, large-scale non-profit organizations and top universities have entered the construction of MOOC in full swing (Kaplan et al., 2016) [3].

\section{Research Methods and Design}

\subsection{Data Source}

The choice of metadata in the Co-word analysis and social network analysis is very important to the show of network structure map, in this the paper we have selected scientific articles from CSSCI (Chinese Social Sciences Citation Index) and SCI database during 1994-2018, choose "MOOC", "Massive Open Online Course" or "Massive Open Online courses" as keywords, finally by fuzzy matching we obtained 627 published articles as valid data set. CSSCI database covers more than 2700 Chinese academic journals of humanities and social sciences, many leading Chinese universities and institutes use CSSCI as a basis for the evaluation of academic achievements and promotion. Therefore, the selected data in this paper can represent the important research in the field of MOOC in China.

\subsection{Research Methods}

This study mainly uses the co-word Analysis, Cluster Analysis and Visual Social Network Analysis. Co-word Analysis based on the statistics of literature basic knowledge unit-keywords' relation degrees to study the coupling relationship between literatures, then we further use the factor Analysis, correlation Analysis and multidimensional scaling Analysis revealed the research hotspot of China's MOOC research. Clustering Analysis and visualization Analysis according to the similarities and differences between Clusters to categorize the research field, then we further discuss the category link and subject structure network by visual network mapping.

\subsection{Research and Design}

Using the literature citations analysis software SATI3.2 exported 627 text data set for Endnote forms in after converted to "Endnote-recommend" form to sample, word frequency statistics and build a co-word matrix, then transform the co-word matrix generates 0 - 1 co-occurrence matrix, finally use the social 
network analysis software Ucinet6 proceed to a series of analysis include centrality analysis, clustering analysis and subgroup analysis, finally we draw the visualization network knowledge mapping by Net draw software, details of design are shown in Figure 1.

\section{Overview of Chinese's MOOC Research}

\subsection{Descriptive Statistics of China's M00C Research}

1) Profile of publications on China's MOOC Research

China's MOOC research began in 2013, by the beginning of 2018, CSSCI and CSI database have a total of 627 published articles about MOOC research, with an average annual number of 125 articles published. From the perspective of publications' number, China's research on MOOC has experienced three stages. As shown in Figure 2, from 2014 to 2015, the research on MOOC began to proliferate. In 2015, a total of 191 articles accounted for $31 \%$ in the total number, which reaching a historical peak. Since 2016, it has entered the deepening stage of research on MOOC. Scholars have been thinking about MOOC from hot to cold. From the perspective of the publication trend, it can be seen that in 2018, the quality of MOOC is estimated to be around 200, indicating that academic groups in this field are still promoting the production and growth of relevant knowledge in MOOC.

2) Group Distribution of Researchers

Publication is the important carrier for academic and professional community to integrate theory and complete scientific academic accumulation work, moreover published scientific articles is also the important carrier for academic community to dialogue and knowledge coding, the metering scholars Alfred Lotka points out that the number of published scientific articles is one of the important measure of the knowledge production in scientific productivity, according to the author's study that the relationship between the number of papers and the authors is inverse square, formula is as follows:

$$
F(n)=\frac{C}{n^{2}}(n=1) \quad(n=1,2,3 \ldots n, n-1)
$$

Generate high frequency keywords

1. Determine the database

2. Select valid data sets

3. Normalized processing of metadata

Text content analysis

1. Descriptive statistics

2. Analysis of research topics

3. Future research trend
Building a co-word matrix (SATI3.2)

1. Convert data set format

2. Extract high-frequency keywords

3. Generate high frequency keyword cooccurrence matrix

Cluster analysis (ucinet)

1. Aggregation subgroup analysis

2. Build visual network map

Figure 1. Research process. 


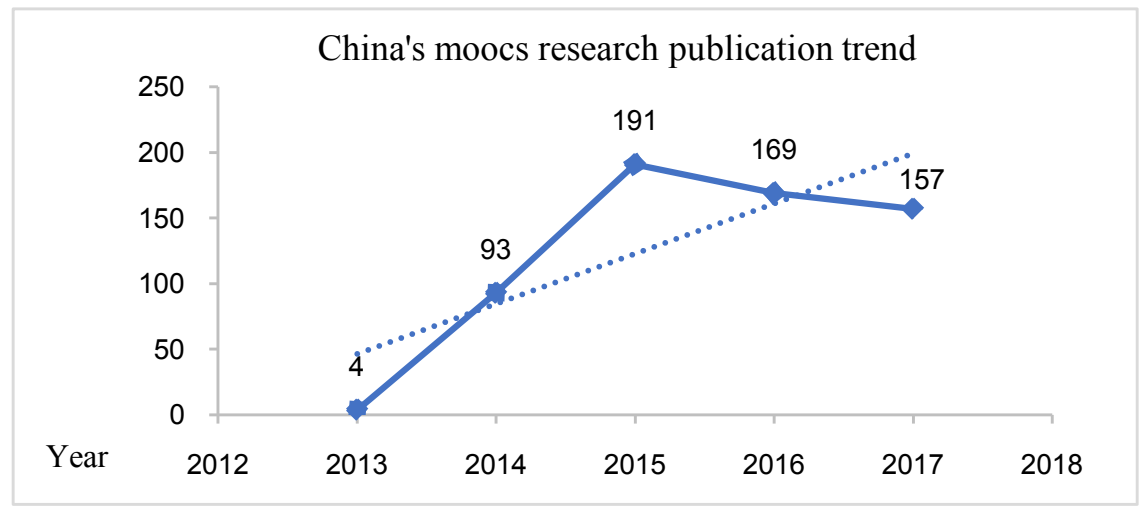

Figure 2. China's MOOC research trend.

$F(n)$ represents the percentage of scholars who published in $\mathrm{n}$ numbers articles account for its overall in a specific field, and $C$ represents the percentage of scholars who published in 1 numbers articles account for its overall. Lotka law reflects the distribution status and maturity of the academic community in a particular field (Alfred J. Lotka, 1926) [4]. This paper conducts field extraction and frequency statistics on China's MOOC research scholars group (the first author) by the literature title analysis software SATI3.2 (see Table 1). Statistics show that 56 scholars have published more than 2 articles, up to 16 (Xiao Junhong), followed by 9 (Wang Qiong) and 7 (Stephen; Liu Hehai), 5 (Fang Xu), 4 (Gao Di; Pan Yantao; Li liang), published 3 articles of 22 scholars (Liu Qiyuan and Ye Ying, 2012) [5].

The statistics of published papers is not a simple stack statistics, its significance lies in reflect Chinese MOOC research scholars' intensification degree and the maturity levels of discipline research, calculated Lotka law values is $91 \%$, which far higher than the Lotka classic formulas $60 \%$, which show that the academic community of MOOC research has not been formed in China, a few academic elite (or academic high yield) is the main producer to promote sustained growth on MOOC research, but the whole study lack of core knowledge production team and collectivization trend of academic groups are too weak.

3) The distribution of research fund

China's MOOC research fund is mainly distributed in national scientific research projects. In the 627 articles published papers, the MOOC study funded by the national and provincial scientific research funds accounted for $16.6 \%, 44$ articles published papers belongs to the national social science fund projects which accounted for $7 \%$, then the MOOC study supported by the national education scientific planning project and national natural fund research accounted for separately as $4 \%$ and $2 \%$, it is worth noting that in the study of MOOC, the national fund project accounts for $83 \%$ of the total fund projects, which is almost five times than Provincial fund project. Theses all reflects an important feature of current China's MOOC research is extensive involvement of state and government agencies, the intervention of state research funding and the top-level 
Table 1. Distribution of major scholars in MOOC.

\begin{tabular}{|c|c|c|c|c|c|c|c|}
\hline Papers & scholar & Papers & scholar & Papers & scholar & scholar & scholar \\
\hline 16 & Xiao Jun-Hong & & Gao Di & & Guo Xiang-Hui & Qian Xiao-long & $\mathrm{Li} \mathrm{Na}$ \\
\hline 9 & Wang Qiong & 4 & Pan Yan-Tao & & Hai Bo Wang & Zhang Mu-Hua & Ju Hong Liu \\
\hline \multirow{2}{*}{7} & $\mathrm{Xu}$ Tao & & Li Yang & & Li Bing & Li Ya-Yuan & Ke Hui Guo \\
\hline & Li Xiao-Ming & \multirow{4}{*}{3} & Zhu Ying & & Li Ya-yuan & \multicolumn{2}{|l|}{ Yang Man-Fu } \\
\hline \multirow{3}{*}{6} & Liu He-Hai & & Qiu Wei-Hua & 3 & Chen Li & \multicolumn{2}{|c|}{ Papers $=3$ scholar's number: 22} \\
\hline & Zhang Shu-Yu & & Li Yan & & Feng Yong-Hua & \multicolumn{2}{|c|}{ Papers $=2$ scholar's number: 22} \\
\hline & Tian Aili & & Li-Jun & & Wang Xiao-Xue & \multicolumn{2}{|c|}{ Papers $>2$ scholar's number: 56} \\
\hline \multirow{2}{*}{5} & Stephen & & Wang Hong-Lin & & Chen Hui-Ruo & \multicolumn{2}{|c|}{ Papers $=1$ scholar's number: 440} \\
\hline & Fang Xu & & Chen Lin & & Li Qi-Bing & \multicolumn{2}{|c|}{ Total number of scholars: 496} \\
\hline
\end{tabular}

system design both continuously push the MOOC research formalization. As shown in Table 2.

\subsection{Hot Topics Distribution of China's MOOC Research}

Due to different factors such as the subject of training, the professional community tend to have different understanding and cognizance of the same construct, but the Cognition of same field scientific community are generally" family resemblance", namely the scientific community based on the similar cognition of subject basic concept and the inherent paradigm to construct the episteme system. As Cohen said: "based on a common paradigm for research, are committed to the same rules and standards to be engaged in practice", co-word analysis method is also based on the inherent rules and considers the research paradigm in specific areas to explore knowledge structure (Thomas Kuhn, 2012) [6].

1) Extraction of co-keywords

Co-keywords, as the most basic knowledge cells, represent the research hotspot of the papers, which is vital node to build a knowledge network. In this study, we obtained 1500 keywords as original data by using SATI3.2, a bibliographic analysis software, then we further normalize the keywords. After normalized operation, the compliance keywords whose word frequency greater than 5 totaled up to 71 , cumulative frequency totaled up to 1735 accounted for more than $84 \%$ of its population, the keywords whose word frequency greater than 10 totaled up to 1597 accounted for $77 \%$. Combining with the distribution of word frequency, it could be preliminarily deduced that Chinese MOOC research focuses on the following aspects: integration of MOOC and flipped classroom, reform of MOOC teaching model, blending learning, learner studies and educational information and so on (see Table 3).

2) Construct the co-occurrence matrix and 2-tuple matrix of high frequency words

Word Co-occurrence Matrix is a multivalued matrix with an asymmetrical relationship, the rows and columns of the Co-occurrence Matrix respectively 
Table 2. Main fund distribution of China's MOOC research.

\begin{tabular}{|c|c|c|c|c|c|}
\hline Frequency & Research fund & PCT & Frequency & Research fund & PCT \\
\hline 44 & National social science fund & $7 \%$ & 1 & Jiangsu science and technology fund & $0.20 \%$ \\
\hline 26 & National education science program & $4 \%$ & 1 & China Scholarship Council & $0.20 \%$ \\
\hline 13 & NSFC & $2 \%$ & 1 & Zhejiang scientific fund & $0.20 \%$ \\
\hline 3 & Hunan social science foundation & $0.50 \%$ & 1 & Sichuan key scientific research fund & $0.20 \%$ \\
\hline 2 & Shaanxi provincial education commission fund & $0.30 \%$ & 1 & Hunan soft science research project & $0.20 \%$ \\
\hline 2 & Jiangsu blue engineering fund & $0.30 \%$ & 1 & National Sci-Tech Support Plan & $0.20 \%$ \\
\hline 1 & China Postdoctoral Science Foundation & $0.20 \%$ & \multicolumn{3}{|c|}{$\begin{array}{l}\text { Fund-supported research accounts for the proportion } \\
\text { of total research: } 16.6 \%\end{array}$} \\
\hline
\end{tabular}

Table 3. Co-keywords of China's MOOC research.

\begin{tabular}{cccccccccc}
\hline No & Keywords & Frequency & No & Keywords & Frequency & No & Keywords & Frequency \\
\hline 1 & MOOC & 324 & 11 & B-Learning & 16 & 21 & OER & 13 \\
2 & flipped classroom & 278 & 12 & big data & 14 & 22 & class teaching & 13 \\
3 & higher education & 30 & 13 & educational information & 14 & 23 & Internet+ & 13 \\
4 & online education & 26 & 14 & Learner & 14 & 24 & online learning & 13 & 12 \\
5 & model of instruction & 24 & 15 & Library & 14 & 25 & MOOC teaching & 12 \\
6 & educational reform & 24 & 16 & online course & 12 & 26 & flipped classroom & 12 \\
7 & college library & 23 & 17 & Innovation & 12 & 27 & influence factor & 12 \\
8 & Micro-lesson & 21 & 18 & distance education & 12 & 28 & information literacy & 11 \\
9 & ideological and & 21 & 19 & Countermeasure & 11 & 29 & business model & & 11 \\
10 & political lesson & China's MOOC & 21 & 20 & curricula construction & 14 & 30 & Educational Technology & 11 \\
\hline
\end{tabular}

represent Specific individuals, the actual value of the matrix represent the strength degree of individual relationships, 0 (or lower than the limit value) is the "hole" in the network that represents the lack of relationships among network nodes, the higher of the actual value (lattice value) in the matrix, the stronger of the real researches' correlation. As shown in Table 4, the actual value of micro lecture and MOOC matrix is 14 and co-occurrence is high, shows that MOOC has a strong correlation with Micro-lesson. Select "Rows/Cols $=18$ " in SATI3.2 to cut the original matrix and further construct a new $18 \times 18$ co-word matrix (see Table 4), "Flipped classroom" and "micro class" have appeared together 24 times in total," Flipped classroom" and "teaching mode" have been presented together 7 times," Online education" and "higher education" appeared in combination 4 times, "Higher education" and "education reform" co-occurred together 3 times in total, which show the strong correlation between each other. Next, we imported the keyword co-occurrence matrix into Ucinet 6 for format conversion, and carry on binary processing for multivalued-matrix, namely 
Table 4. Co-occurrence matrix of Co-keywords (part).

\begin{tabular}{cccccccc}
\hline $\begin{array}{c}\text { co-occurrence } \\
\text { frequency }\end{array}$ & MOOC & $\begin{array}{c}\text { higher } \\
\text { education }\end{array}$ & $\begin{array}{c}\text { online } \\
\text { education }\end{array}$ & $\begin{array}{c}\text { model of } \\
\text { teaching }\end{array}$ & reform & $\begin{array}{c}\text { college } \\
\text { library }\end{array}$ & Micro-lesson \\
\hline MOOC & 324 & 11 & 15 & 15 & 12 & 16 & 14 \\
higher education & 11 & 26 & 4 & 0 & 3 & 0 & 0 \\
online education & 15 & 4 & 24 & 2 & 1 & 0 & 0 \\
model of teaching & 15 & 0 & 2 & 24 & 0 & 0 & 1 \\
reform & 12 & 3 & 1 & 0 & 23 & 0 & 0 \\
college library & 16 & 0 & 0 & 0 & 0 & 21 & 0 \\
Micro-lesson & 14 & 0 & 0 & 1 & 0 & 0 & 21 \\
\hline
\end{tabular}

convert the multivalued matrix to the $0-1$ matrix (binary matrix), shown in Table 5 represents the weak connection relation between matrix individuals, 1 represents the strong connection relation between matrix individuals, and it is obvious that binary matrix is crucial to present a significant visual map.

3) Clustering analysis of co-keywords

Identifying the "Cohesive Subgroups" of the knowledge network is a continuous focus on social network analysis; cluster divides individuals into factions based on their similarity within the group and their distance from each other (John Scott, 2007) [7]. High frequency word co-occurrence matrix is normalized to a similarity matrix by the software Ucinet6, and then we use hierarchical cluster analysis construct cluster tree, as shown in Figure 3.

Condensing subgroup has a hierarchical structure, architectural group contained in the boy group. Cluster tree of condensing subgroup is the key to clearly show the subgroup level rather than a simple classified according to the characteristics, from the clustering tree we can see that China MOOC researches are mainly divided into the third group: first knowledge group include flipped classroom, Internet+, Ideological and political education in colleges and universities, University libraries, higher education, course construction, online learning, large agglomeration subgroups include small groups; the second knowledge group include teaching mode, teaching reform, education informatization, learners, online education, countermeasures, innovation, online open courses, big data, remote education and open education resources; the third knowledge group include micro-course, MOOC, education and mixed teaching. Therefore, On the basis of aggregation sub-cluster analysis and combined with high frequency co-occurrence matrix, China's MOOC research can be divided into three major fields, namely, research on construction and application of MOOC in higher education, especially in universities, research on MOOC teaching mode and online education research, and hybrid teaching research combining traditional classroom teaching with MOOC.

\subsection{Visual Analysis and Focus on Hot Topics}

"Network" is a dynamic collection which made of node and the connection 
Table 5. 2-tuple matrix of Chinese MOOC research (part).

\begin{tabular}{cccccccc}
\hline item & MOOC & $\begin{array}{c}\text { higher } \\
\text { education }\end{array}$ & $\begin{array}{c}\text { online } \\
\text { education }\end{array}$ & $\begin{array}{c}\text { model of } \\
\text { teaching }\end{array}$ & reform & $\begin{array}{c}\text { college } \\
\text { library }\end{array}$ & Micro-lesson \\
\hline MOOC & 1 & 1 & 1 & 1 & 1 & 1 & 1 \\
higher education & 1 & 1 & 1 & 1 & 1 & 1 & 0 \\
online education & 1 & 1 & 1 & 1 & 1 & 1 & 1 \\
model of teaching & 1 & 0 & 1 & 1 & 0 & 1 & 1 \\
reform & 1 & 1 & 1 & 1 & 1 & 1 & 0 \\
college library & 1 & 1 & 0 & 1 & 0 & 0 & 0 \\
Micro-lesson & 1 & 1 & 0 & 0 & 0 & 0 & 1 \\
\hline
\end{tabular}

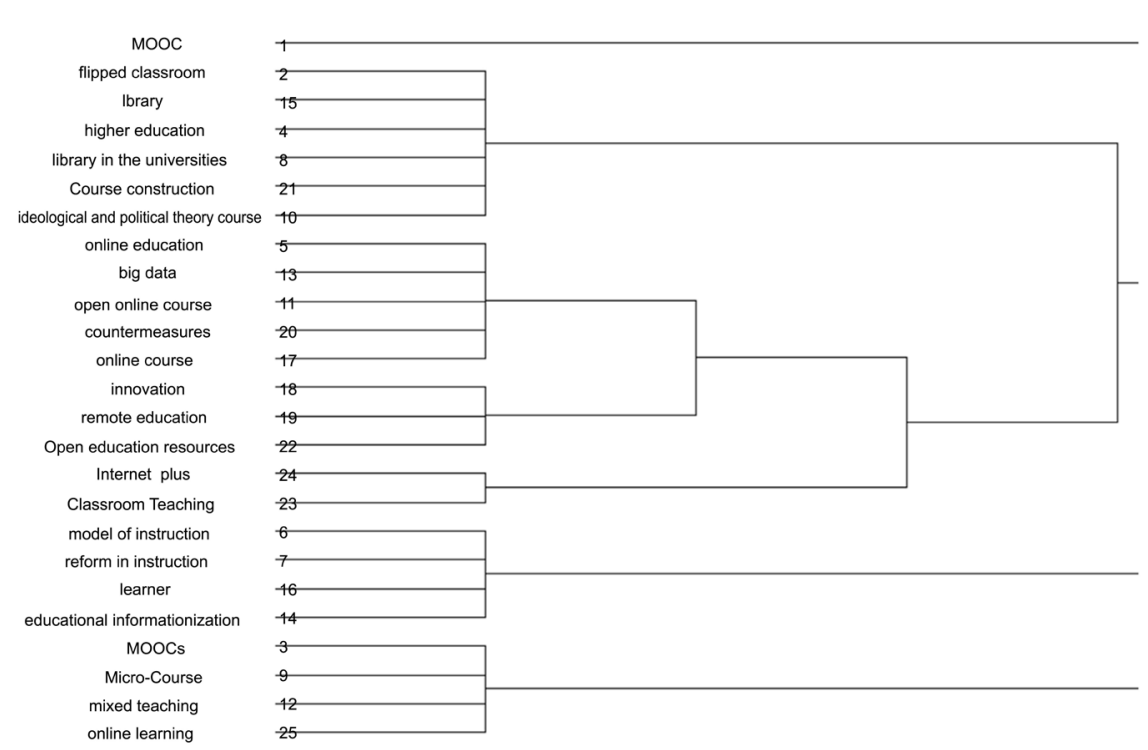

Figure 3. Cluster tree of China MOOC research.

between node, against the background of globalization inter-disciplinary research, the study of Chinese MOOC Network structure is far too complex, but the advance of visualization Network analysis techniques provided an applicable research tool for us to explore Chinese MOOC research academic community and its knowledge structure. The knowledge Network map revealed the overall of MOOC domain knowledge, like a bird looking down at the earth. In this study, we import the based on the foregoing 0 - 1 matrix has been constructed, namely binary matrix, to visualization program NetDraw, and we use "the Visualize-NetDraw" built the visualization network diagram, mean while Layout the diagram by "GMS (Gower Metric Scaling Layout)" in NetDraw.GMS based on the direct or indirect relationship between network nodes and combined with hierarchical clustering algorithm, to construct a visualized network graph with clustering effect, and finally forms a knowledge partition, as shown in Figure 4.

The visual network structure map based on the Gower partition contains Gower partition network density, the core-edge structure, clustering and so on a 


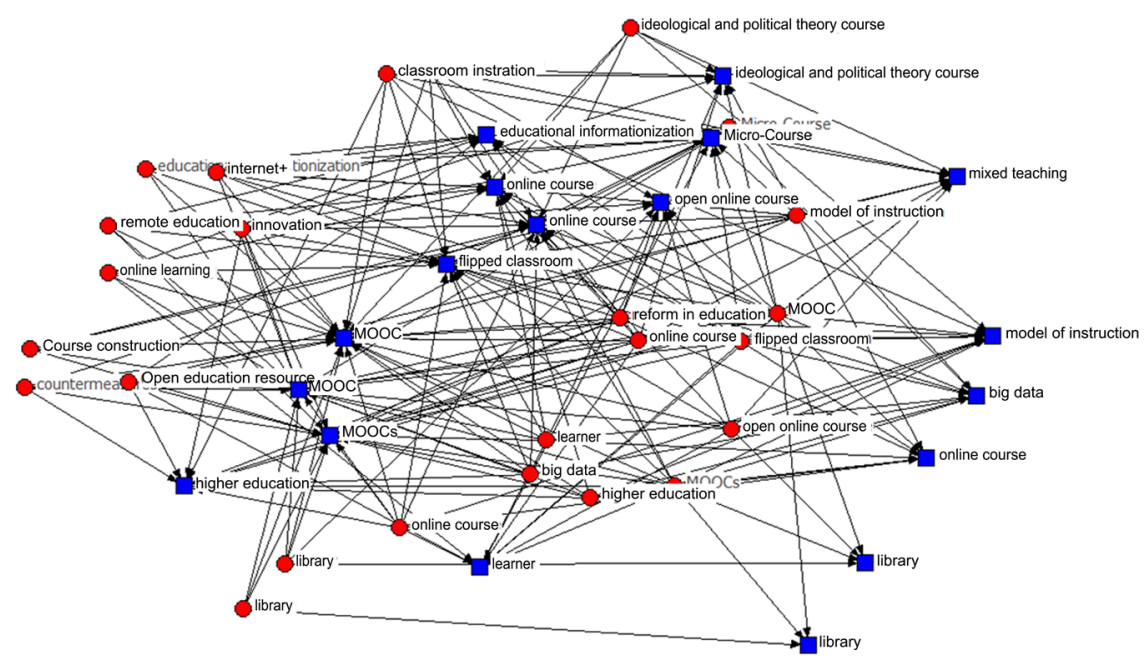

Figure 4. A visual network structure based on the Gower partition.

large amount of information, each node in the network characterization of a high frequency in the study of Chinese MOOC keywords, the size of nodes is characterization of the nodes' importance in whole network, the length of the directed line means distance and connection path between different nodes. Number 1 represents "strong connection" relationship, in the visualization network diagram MOOC nodes in the network core position and is the largest number, this is consistent with the scientific practice that MOOC as the core to detonate a series of related study in China. Based on the visualization knowledge map and clustering tree graph, we found out that the research hotspot of China's MOOC research is as follows:

1) Countermeasure research on the development of MOOC

According to the visualization network map results which based on Gower partition, the two knowledge nodes of "MOOC" and "countermeasure" are located far from the network center in the edge area of the network, but a "knowledge sub-group" with MOOC and countermeasure as the core is formed. To this day have 5 years away from "the first year of development of China's MOOC" in 2013, China has united many famous academicians who from 220 top universities across the country, opened 490 course in the nine MOOC Platform, total quantity of MOOC already ranked first in the world. But along with the MOOC Platform widening and MOOC Courses development, the problems for localization of MOOC continuously emerging, hence the development status and countermeasure research of MOOC became one of the hot topics. Through qualitative study and quantitative analysis, we found that the research on this topic includes the localization construction of MOOC, the construction of MOOC platform, the construction of MOOC curriculum and development status and countermeasures of MOOC in higher education.

2) The research of educational information for MOOC

The information subject of MOOC education is composed of Internet+, remote education, online learning, flipped classroom and online education nodes: 
a) research on the topic of Internet+ MOOC mainly focuses on the form research of MOOC education in the context of Internet+, the theoretical research on the value orientation of MOOC education, the research of new talent cultivation model, and the research on the concept of Internet+ education; b) The formation of long-distance education nodes mainly lies in the fact that the production of MOOC injects a large amount of fresh blood and high-quality education resources into long-distance education, some scholars believe that MOOC further refine the differential target positioning of distance education teaching, and it has become a strategic tool for remote education to break the bottleneck of low education resources and achieve a major breakthrough (Wang Haibo, Li Jinfeng, 2016), Therefore, the study on the fusion of MOOC and remote education has become a new research hotspot (Wang Haibo and Li Jinfeng, 2016) [8]. c) As for online learning node, it focuses on the empirical research of online learning process and effect evaluation with MOOC as the core. Among them, online learning and online education are adjacent nodes, which are closely related; d) Flipped classroom is located in the important position of "bridging" in the network diagram and has large nodes. The comparative analysis of features and model fusion of new teaching modes, such as flipped classroom and MOOC, is becoming increasingly hot. In particular, the comparative study of MOOC and flipped classroom has become the focus of academic community research in this field; e) Online education is a "relatively isolated" node in the information subject of MOOC education, which is far away from other sub-topics. Online education research mainly focuses on the status quo of online education, comparative analysis of online education between China and the United States, and empirical research on the development motivation of online education.

3) A hybrid teaching study of classroom teaching and MOOC online teaching

The third knowledge map partition is constituted by several large nodes, classroom instruction, ideological and political theory course, MOOC, blended learning and so on. This topic focuses on the integration of online education teaching in MOOC and traditional classroom teaching modes. In specific course teaching, the fusion practice research of traditional classroom teaching for ideological and political theory versus teaching model of MOOC is the most comprehensive study, which we can see in the knowledge map is that the ideological and political theory course has become a new node outside the classroom teaching, and this node is located at the "bridging" position between MOOC and classroom teaching. This research focuses on the combination of MOOC and ideological and political courses in colleges and universities or in other specific traditional disciplines, mainly consist of curriculum design, evaluation system, Specific teaching activity organization, research of teaching efficiency and so on micro-teaching inquiry. The purpose of this study is to improve teaching quality and cultivate innovative talents based on the Internet era, most of all, the practical exploration of blended teaching mode and teaching courses has become one of the key topics in the research of MOOC, for example a practical study on the 
mixed teaching courses of Peking University by the teacher development center of Peking University.

4) Research on MOOC and innovation of higher education

Higher education, curriculum construction, teaching mode, online course, online open course, innovation and teaching reform are grouped to form the knowledge sub-group of MOOC and higher education innovation and reform, among them teaching model, curriculum construction and innovation is the biggest node and at the center of the cluster. The distance between each node is close and the network density is large, This theme is mainly divided into the following sub-areas: a) The hot topics of research on MOOC curriculum construction focus on the research of the MOOC curriculum, course construction path, course utilization and practical research on application-oriented undergraduate curriculum construction; b) Comparative analysis and reference research on MOOC and online open courses, online courses and other online courses, for example the research on course credit recognition based on online open course, research on features comparison between MOOC and flipped classroom and so on; c) In the knowledge network map, teaching reform, as an important node, is loosely connected with other nodes, it is an important transition node between MOOC hybrid teaching research and higher education innovation research.

5) Research on open education resources of MOOC

The theme of MOOC open education resource include learners, micro-courses, MOOC, open education resources and big data, except big data as the transition topic, other nodes is closely between each other. The rise of MOOC is due to the Open education resources (OER) movement abroad, In 2001 MIT announced that it would put all its courses online, and further officially launch the open course program, this action triggers the global OER movement, so the open education resources is the core concept of MOOC research, research on open education resource movement and value orientation of MOOC. However, studies on the values of open education resource movement and MOOC, core concept of MOOC, the reflection and future prospect of MOOC, the humanistic value and learner study of education, the development of big data and MOOC, and the balanced development of MOOC and education resources have become new research hotspots.

6) Research on the application of MOOC in university libraries

Different from the intellectual production of academic institutions, MOOC's application research of the library in colleges and universities are mostly from institutions' MOOC practice under the push of technology research and development, the research of this field focused on the role of university library of MOOC environment change, the study of MOOC service in university library, research on the role positioning of library services, the research on the copyright services of library MOOC, research on the effect of opening education in university libraries, which have provided a vast field to be cultivated for multidisciplinary researchers. 


\section{Conclusion}

The efforts reported in this paper offer several contributions to the scholars, researchers, and students discover. First, in this study, the document analysis software-SATI and Social network analysis software-Ucinet6 are both used to as analysis tools, select CSSCI and SCI database, and MOOC related papers published in 1994-2018 were taken as the specific research objects. By using such statistical methods as co-word analysis and clustering analysis explored hot topics and future. Our results reveal that the research hotspot of MOOC in China focuses on the development countermeasures of MOOC, the informatization of MOOC education, the hybrid teaching of classroom teaching and MOOC online teaching, the innovation and reform of MOOC and higher education, the application research of MOOC and open education resources and MOOC in university libraries. Our research results enable scholars to quickly and visually understand the status quo, research hotspots and research trends of MOOC in China in the past 4 years.

Second, the scholars and researchers should realize that China's MOOC research knowledge network has been preliminarily formed, but some academic elites are the main force in the production of MOOC knowledge. Compared with the mature field research, China's professional academic groups for MOOC research have not yet been formed.

Third, in the future, China's MOOC research should strengthen the university knowledge production cooperation between institutions and scholars, and contribute to the production of professional academic organizations, in the concrete research content on MOOC education of humanistic value and learner study, MOOC teaching model of classroom teaching and online teaching hybrid research, sustainable development and the MOOC application research is relatively weak, needs to be professional community to further explore in this field.

In general, this paper established the knowledge map of China's MOOC research, provided data support for scholars to understand China MOOC research hotspots, and also provided clear reference the future study, which can both promote the future research and practice of MOOC.

\section{Conflicts of Interest}

The authors declare no conflicts of interest regarding the publication of this paper.

\section{References}

[1] Zancanaro, A. and de Souza Domingues, C. (2018) Massive Open Online Courses (MOOC) for Teacher Portuguese. Journal of Distance Education, 16, 18-34.

[2] Multon, S., Pesesse, L., Weatherspoon, A., Florquin, S., Van de Poel, J.-F., Martin, P., et al. (2018) A Massive Open Online Course (MOOC) on Practical Histology: A Goal, a Tool, a Large Public! Return on a First Experience. Annales de Pathologie, 38, 76-84. https://doi.org/10.1016/j.annpat.2018.02.002 
[3] Kaplan, A.M. and Haenlein, M. (2016) Higher Education and the Digital Revolution: About MOOC, SPOCs, Social Media, and the Cookie Monster. Business Horizons, 59, 441-450. https://doi.org/10.1016/j.bushor.2016.03.008

[4] Lotka, A.J. (1926) The Frequency Distribution of Scientific Productivity. Journal of the Washington Academy of Sciences, 16, 317-323.

[5] Liu, Q.Y. and Ye, Y. (2012) Realization of Document Title Information Mining Technology and Its Software SATI-A Case Study of Chinese and Foreign Book Informatics. Journal of Information Resource Management, 16, 29-35.

[6] Kuhn, T.S. (2012) The Structure of Scientific Revolution. Translated by Fu Dawei, Cheng Shude, Wang Daoyuan. Peking University Press, Beijing, 1-203. https://doi.org/10.7208/chicago/9780226458144.001.0001

[7] Scott, J. (2007) Social Network Analysis. Translated by Liu Jun. Chongqing University Press, Chongqing, 3, 1-213.

[8] Wang, H.B. and Li, J.F. (2016) Differential Target Positioning of China Network Remote Education in the Context of MOOC. China Remote Education, 4, 78-82. 